\title{
NOTA SOBRE A OCORRÊNCIA NATURAL DO BUTIÁ-ANÃO \\ (BUTIA LALLEMANTII DEBLE \& MARCHIORI) \\ NO CERRO DO JARAU, QUARAÍ - RIO GRANDE DO SUL ${ }^{1}$
}

\author{
FABIANO DA SILVAALVES² JOSÉ NEWTON CARDOSO MARCHIORI ${ }^{3}$
}

\section{RESUMO}

A ocorrência natural de Butia lallemantii Deble \& Marchiori é confirmada para o município de Quaraí, RS, próximo ao topo do Cerro do Jarau. Desta população, consta em herbário pelo menos um espécime, identificado como Butia paraguayensis (Barb. Rodr. ) L.H. Bailey.

Palavras-chave: Butia lallemantii, Arecaceae, Cerro do Jarau, Quaraí, Rio Grande do Sul.

\section{SUMMARY}

[Note on the natural occurrence of Butia lallemantii Deble \& Marchiori in Jarau Mountain, municipality of Quaraí, Rio Grande do Sul state, Brazil].

The natural occurrence of Butia lallemantii Deble \& Marchiori is confirmed to the municipality of Quaraí, Rio Grande do Sul state (Brazil), close to the top of Jarau Mountain. A specimen, at least, was formerly collected from this population and misidentified as Butia paraguayensis (Barb. Rodr.) L.H. Bailey.

Key words: Butia lallemantii, Arecaceae.

\section{INTRODUÇÃO}

Conhecido desde o relato de Robert AvéLallemant ${ }^{4}$, médico e naturalista que excursionou pelo sul do Brasil em meados do século XIX, o butiá-anão ou butiazeiro-anão do Rio Grande do Sul figura, invariavelmente, na literatura botânica do século 20 e do início do século 21, como Butia paraguayensis (Barb. Rodr.) Bailey (Mattos, 1977; Marchiori, 1992;

1 Recebido em 10-7-2010 e aceito para publicação em 18-8-2010.

2 Biólogo, MSc, doutorando do Programa de PósGraduação em Engenharia Florestal da Universidade Federal de Santa Maria. Professor da Universidade da Região da Campanha, URCAMP - Alegrete.

3 Engenheiro Florestal, Dr.Professor Titular do Departamento de Ciências Florestais da UFSM. Bolsista de Produtividade em Pesquisa (CNPq - Brasil).

4 "Quando, de manhã, saí de Tapevi, a minha atenção foi despertada por uma planta grosseira de um cinzento brilhante que, em moitas herbáceas, cobria encostas inteiras, em milhares de exemplares. Apeei-me e encontrei inumeráveis palmeirinhas truncadas ou frondes de palmeiras que tinham todos os atributos da palmeira, menos o estipe, pois as folhas de um a dois pés de comprimento, pinatífidas como na maioria das palmeiras, saem diretamente do chão" (Avé-Lallemant, R. Viagem pela província do Rio Grande do Sul (1858). Belo Horizonte, Ed. Itatiaia; São Paulo, Ed. da Universidade de São Paulo, 1980. p. 359).
Marchiori, 1995; Marchiori et al., 1995; Marchiori, 2004), binômio inválido por corresponder a espécie distinta.

Elemento conspícuo nos campos arenosos do oeste e sudoeste gaúcho, notadamente de São Francisco de Assis, Manoel Viana e Alegrete, o butiá-anão foi descrito apenas em 2006, sob o nome de Butia lallemantii Deble \& Marchiori, homenagem ao viajante alemão anteriormente referido (Deble \& Marchiori, 2006).

A presente nota visa a registrar a ocorrência natural de Butia lallemantii no Cerro do Jarau, município de Quaraí, RS.

\section{NOTA DE OCORRÊNCIA}

Por ocasião de viagem de estudos ao município de Quaraí, em dezembro de 2009, encontrou-se uma pequena população de palmeiras de estipe curto, em afloramentos areníticos da encosta norte do Cerro do Jarau (30 $11^{\circ}$ ' $19^{\prime \prime} \mathrm{S}$, $56^{\circ} 30^{\prime} 01^{\prime \prime}$ W e $285 \mathrm{~m}$ de altitude), próximo a seu topo. O exame do material coletado, não deixa margem a dúvida: trata-se de Butia lallemantii Deble \& Marchiori (Figura 1), espécie de hábito cespitoso, típica de solos arenosos do oeste e sudoeste gaúcho, bem como do topo de alguns morrotes de arenito, caso dos 

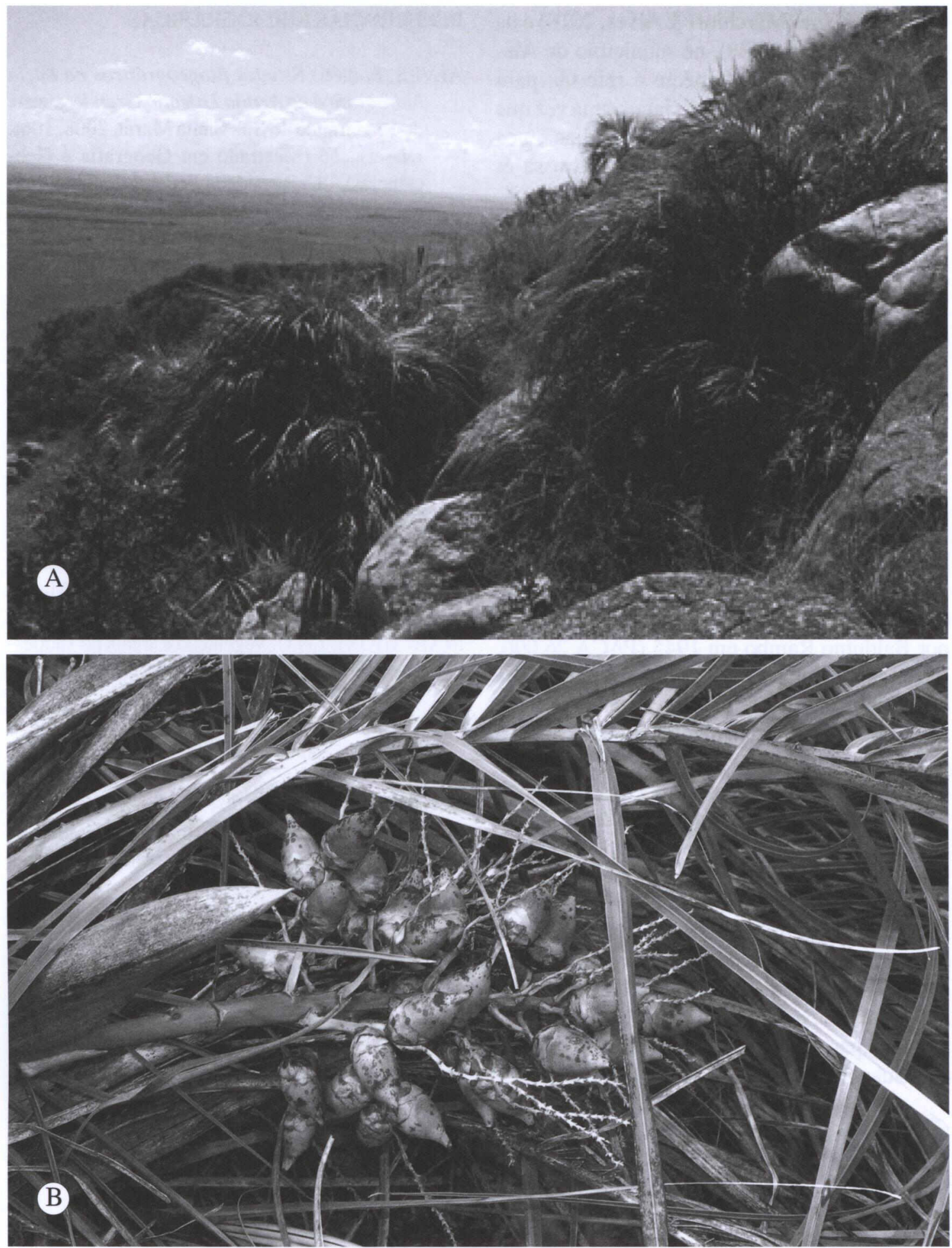

FIGURA 1 - Registro fotográfico do butiá-anão (Butia lallemantii) no Cerro do Jarau. A - Aspecto geral da população, próximo ao topo do Cerro. B - Folhas, espata e frutos jovens. 
Cerros do Tigre (Marchiori \& Alves, 2010) e da Cascavel (Alves, 2008), no município de Alegrete. No Uruguai, a espécie é referida para ambientes semelhantes ao do Jarau, uma vez que ocorre em "Cerros Chatos" e "Cornijas", nos departamentos de Rivera e Artigas (Brussa \& Grela, 2007).

A Figura 1A mostra dois agrupamentos de butiá, em primeiro plano, e um terceiro ao fundo, com estipe curto, exposto por erosão. A Figura 2B ilustra, em parte, a espata lenhosa, que é aguda, lisa, glabra e opaca, externamente; a infrutescência, vista em detalhe, apresenta raque de aproximadamente $25 \mathrm{~cm}$ e cerca de 25 ráquilas primárias, com frutos ovado-lanceolados, de ápice acuminado. $\mathrm{Na}$ mesma imagem, vê-se, ainda, a parte central de uma folha pinada, com pinas foliares dispostas em dois planos e mais afastadas entre si do que largura das mesmas.

Da população encontrada no Cerro do Jarau, consta em herbários pelo menos uma coleta, feita por Balduíno Rambo em 1945 (PACA 26.090, Fazenda do Jarau, p. Quaraí, in rupestribus dumetosis, fr. submaturo). Na etiqueta, fica-se sabendo que o material, identificado por Emrich \& Rambo como Butia bonneti (Linden) Becc. (5-9-1954), foi considerado por L.R. Noblick (22-5-1992) como Butia paraguayensis (Barb. Rodr.) L.H. Bailey.

No tocante à distribuição geográfica, o presente registro de Butia lallemantii no Cerro do Jarau destaca-se por ser o ponto mais ocidental de ocorrência da espécie, até o momento conhecido. Distante cerca de $100 \mathrm{~km}$ da população mais próxima, os dois pontos estão geograficamente separados pelo Planalto da Campanha, com suas rochas vulcânicas e solos rasos.

\section{REFERÊNCIAS BIBLIOGRÁFICAS}

ALVES, F. da S. Estudos fitogeográficos na bacia hidrográfica do Arroio Lajeado Grande - oeste do Rio Grande do Sul. Santa Maria, 2008. 106f. Dissertação (Mestrado em Geografia e Geociências) - Universidade Federal de Santa Maria.

AVÉ-LALLEMANT, R. Viagem pela província do Rio Grande do Sul (1858). Belo Horizonte: Ed. Itatiaia; São Paulo: Ed. da Universidade de São Paulo, 1980. 417 p.

BRUSSA SANTANDER, C.A.; GRELA GONZÁLEZ, I.C. Flora arbórea del Uruguay. Con énfasis en las especies de Rivera y Tacuarembó. Montevideo: COFUSA, 2007. 542 p.

DEBLE, L.P.; MARCHIORI, J.N.C. Butia lallemantii, uma nova Arecaceae do Brasil. Balduinia, Santa Maria, n. 9, p. 1-3, 2006.

MARCHIORI, J.N.C. Areais no sudoeste do Rio Grande do Sul: Elementos para uma História Natural. Ciência \& Ambiente, Santa Maria, n. 5, p. 65-89, 1992.

MARCHIORI, J.N.C. Vegetação e areais no sudoeste rio-grandense. Ciência \& Ambiente, Santa Maria, n. 11, p. 81-92, 1995.

MARCHIORI, J.N.C. Fitogeografia do Rio Grande do Sul: Campos Sulinos. Porto Alegre, EST, 2004. $110 \mathrm{p}$.

MARCHIORI, J.N.C.; ALVES, F. da S. Campos de areia e silvicultura no oeste do Rio Grande do Sul: enfoque fitogeográfico. Balduinia, Santa Maria, n. 24, p. 1-11, 2010.

MARCHIORI, J.N.C.; ELESBÃO, L.E.G.; ALVAREZ-FILHO, A. O palmar de Coatepe. $\mathrm{Ci}$ ência \& Ambiente, Santa Maria, n. 11, p. 93104, 1995.

MATTOS, J.R. Palmeiras do Rio Grande do Sul. Roesssléria, Porto Alegre, v. 1, n. 1, p. 5-94, 1977. 